\title{
USING SATELLITE REMOTE SENSING TO ASSESS EVAPOTRANSPIRATION: CASE STUDY OF THE UPPER EWASO NG'IRO NORTH BASIN, KENYA
}

\author{
Jeniffer Kinoti Mutiga ${ }^{* *}$, Zhongbo $\mathrm{Zu}^{1}$, and Tsahaei Woldai ${ }^{1}$ \\ ${ }^{*}, 1$ International Institute for Geo-Information Science and Earth Observation (ITC), \\ P.O Box 6, 7500 AA, Enschede, The Netherlands.
}

Keywords: SEBAL, Actual Evapotranspiration, Remote Sensing, Landcover/ Landuse, NDVI, Radiation, Energy Balance, and Heat Fluxes

\begin{abstract}
:
Actual Evapotranspiration $\left(\boldsymbol{E} \boldsymbol{T}_{\boldsymbol{a}}\right)$ is one of the most useful indicators to explain whether the water is being used as "intended". $\boldsymbol{E} \boldsymbol{T}_{\boldsymbol{a}}$ variations, both in space and time and from different land use types are seen to be highly indicative for the adequacy, reliability and equity in water use; the knowledge of these terms is essential for judicious water resources management. Unfortunately, $\boldsymbol{E} \boldsymbol{T}_{a}$ estimation under actual field conditions is still a big challenge to both scientists and water managers. The complexity associated with the estimation of $\boldsymbol{E} \boldsymbol{T}_{\boldsymbol{a}}$ has lead to the development of various methodological approaches for estimating it over time.

During the last two to three decades, significant progress has been made to estimate actual evapotranspiration using satellite remote sensing These methods provide a powerful means to compute $\boldsymbol{E} \boldsymbol{T}_{\boldsymbol{a}}$ from pixel to the entire basin scale. In this study, Surface Energy Balance Algorithm for Land (SEBAL) was used to compute a complete radiation and energy balance along with the resistances for momentum, heat and water vapour transport for each pixel and then applied to assess the $\boldsymbol{E T}_{\boldsymbol{a}}$ at the basin scale and subsequently carryout a simple water balance for the basin. This was done for the Upper Ewaso Ng'iro North River Basin, in Kenya. Landcover/ landuse for 2000, 2003 and 2006 were assessed and compared with $\boldsymbol{E} \boldsymbol{T}_{\boldsymbol{a}}$ for the same periods and a significant correlation was established. The $\boldsymbol{E} \boldsymbol{T}_{\boldsymbol{a}}$ values obtained for the three time periods was used to analyse water use patterns across the basin thus giving insights on the underlying factors impacting on the water resources of the basin and hence facilitating the formulation of appropriate water resources management strategies for the basin.
\end{abstract}

\section{1. .INTRODUCTION}

Since water resources management strategies are usually formulated on basin scale, understanding of the hydrological processes at this scale is a pre-requisite for implementation of these strategies. Increasing pressure on water resources requires a sound knowledge of where, when and how much water is used. Evapotranspiration (ET) is an important factor for evaluating water productivity and monitoring of irrigation performance. Evapotranspiration is a process governed by the energy and heat exchanges at the land surface, with the upper bound being constrained and controlled by the amount of available energy and water respectively (Hemukamara et al., 2003). However, direct measurement of actual evapotranspiration is difficult and most cases only provides point values.

Quantitative analysis of various components of the hydrological cycle within a river basin is essential for systematic planning and management of the water resources. Although ET is one of the most important components of the hydrological cycle, it is one of the most difficult to measure especially under composite terrains (Wu et al, 2006). Traditionally, total evaporation (ET) from agricultural fields has been estimated by multiplying the potential evapotranspiration $\left(\mathrm{ET}_{\mathrm{o}}\right)$ by crop coefficients $\left(\mathrm{K}_{\mathrm{c}}\right)$ determined according to the crop type and the crop growth stage as highlighted in Allen et al., 1998.

Actual Evapotranspiration $\left(\mathrm{ET}_{\mathrm{a}}\right)$ is one of the most useful indicators to explain whether the water is being used as "intended" or not. $\mathrm{ET}_{\mathrm{a}}$ variations, both in space and time and from different land use classes (particularly agricultural lands) are thought to be highly indicative for the adequacy, reliability and equity in water use; the knowledge of these terms is essential for judicious water resources management. Unfortunately, $\mathrm{ET}_{\mathrm{a}}$ estimation under actual field conditions is still a very challenging task for scientists and water managers. The complexity associated with the estimation of ET has lead to the development of various methods for estimating this parameter over time Allen et al., 1998.

Using recent developments in the field of remote sensing application in water management, this paper shows that remote sensing tools can help in improving water management by providing information on the existing patterns of water use; identifying the weaknesses in the approach to water management; and assisting in identifying the potential areas where there are opportunities for improving water use efficiency.

In a semi-arid environment, ET from the land surface plays a critical role not only in water circulation within that surface, but also in many associated physical and ecological variables, such as atmospheric dynamics, subsurface water storage, and vegetation growth. Spatial variability in landuse, landcover, soil properties and water flows, most hydro-meteorological parameters exhibit an evident spatial variation, which cannot be obtained from a limited number of synoptic observations. This problem however, can be overcome by applying a physically based multi-step SEBAL formulated by Bastiaanssen, 1995. This study attempted to estimate the temporal change and spatial distribution of evapotranspiration and other components of the surface heat budget in the Ewaso Ng'iro North River Basin in Kenya during a rainy season from 2000 to 2006.

Evapotranspiration data enhances the understanding underlying factors that impact on water use and subsequently taking

*Corresponding Author Email: mutiga@itc.nl 
appropriate interventions for different critical water uses, like irrigated agriculture, (Bastiaanssen et al., 2001). If reliable and consistent information regarding evapotranspiration can be accessed at low cost, it can be used to analyze the performance of for example irrigation systems and devise better management strategies. Remote sensing is one such an alternative, and as such, over the last decade, methods for calculating the actual evapotranspiration $\left(\mathrm{ET}_{\mathrm{a}}\right)$ have been developed (Bastiaanssen, 1995). The main advantage of this approach is that large areas are covered, and that data is easily obtainable without extensive monitoring networks in the field (Bandara, 2003; Chemin et al., 2004). In summary the objectives of this study is to use satellite images to estimate spatio temporal variation of actual evapotranspiration across the basin from 2000 to 2006 .

\section{THE STUDY AREA}

The Ewaso Ng'iro basin is the largest out of the five major drainage basins that make up the Kenyan drainage network, and covers $210,226 \mathrm{~km} 2$ thus representing about $37 \%$ of the total area and contributes only about $7 \%$ of the total annual river flows. The basin constitutes the upper stream section of this drainage area, covering $15,251 \mathrm{~km} 2$. It is situated between latitudes $0^{\circ} 20^{\prime}$ south and $1^{\circ} 01^{\prime}$ 'north and longitudes $36^{\circ} 10^{\prime}$ east and $38^{\circ} 00^{\prime}$ east as defined by the natural topographic divide. The Upper Ewaso $\mathrm{Ng}$ 'iro basin drains from the Rift Valley escarpment to the west, the Nyandarua ranges to the north west, the Mt. Kenya to the south, the Nyambene hills in the east, and the Mathews ranges to the north while the downstream outlet is at Archers post.

The eastern region of the basin has a clear bimodal distribution with highest rainfall in April and October (Berger, 1989) while in the western and north western region, beside the rainfall being bimodal pattern, continental rainfall is also experienced between June and September. The basin is a highland-lowland system and changes in elevation gives rise to a dramatic climate and ecological gradient, from humid moorlands and forests on the slopes to arid Acacia bushland in the lowland, with a diverse pattern of landuse (Decurtins, 1992). Most part of the basin is located in the leeward slopes of Mt. Kenya while the other part is in the windward slopes of the Nyandarua ranges, thus making it predominantly an ASAL region. Rainfall amounts are low, ranging from $2000 \mathrm{~mm}$ on the Nyandarua Ranges, to under 365 $\mathrm{mm}$ per annum in the drier north eastern areas with mean annual rainfall of about $700 \mathrm{~mm}$. Despite this relatively high amount of rainfall, the distribution is such that the seasonal amounts are insufficient for proper crop growth in most parts of the basin.

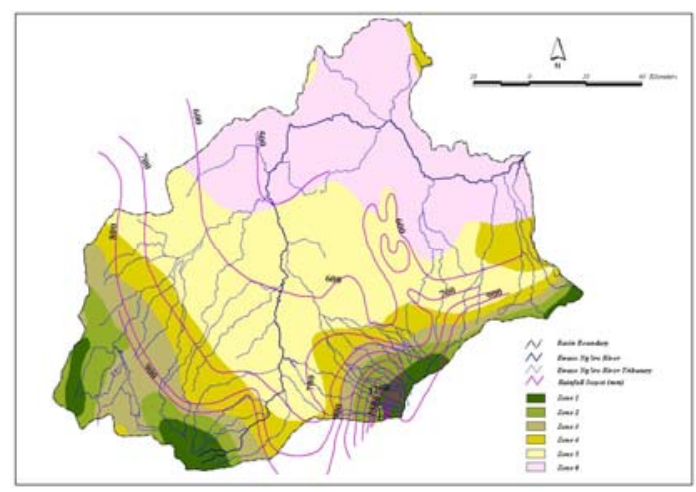

Figure 2: The Upper Ewaso Ng'iro Baisn

\section{MATERIALS AND METHODOLOGY}

MODIS L1B data which is an archive of 36 channels of visible and near-infrared reflectance and radiance, and thermal-infrared radiance was used. A total of 30 cloud free images covering the study area for 2000, 2003 and 2006, were downloaded from the satellite active archive's website

http://edcimswww.cr.usgs.gov/pub/imswelcome/. The images were processed to provide the necessary data required for the estimation of the areal evapotranspiration using the surface energy balance algorithm for land (SEBAL) approach.

\subsection{Surface Energy Balance Algorithm for Land (SEBAL)}

The Surface Energy Balance Algorithm for Land (SEBAL) is a relatively new parameterization of the energy balance and surface fluxes based on spectral satellite measurements. SEBAL requires spatially distributed Visible, Near-infrared and Thermal infrared input data, from satellite imageries. SEBAL parameterization is an iterative and feedback-based numerical procedure that deduces the radiation, heat and evaporative fluxes. The algorithm computes most essential hydrometeorological parameters and requires little field information (only incoming solar radiation, air temperature and wind speed data are required), (Bastiaanssen, 1998a \&b, 2000). The energy balance during the satellite overpass and the integrated 24HRS fluxes are computed on pixel by pixel basis.

The model comprises of a number of computational steps for image processing and finally calculates the actual evapotranspiration $\left(E T_{a}\right)$ as well as other energy exchanges between land and atmosphere. By ignoring energy required for photosynthesis and the heat storage in vegetation, and in its most simplified form SEBAL reads as: $R_{n}=G_{0}+H+L E$ where $R_{n}$ is the net radiation absorbed at the land surface (W/m2), $G_{0}$ the soil heat flux to warm or cool the soil $(\mathrm{W} / \mathrm{m} 2), \mathrm{H}$ the sensible heat flux to warm or cool the atmosphere $(\mathrm{W} / \mathrm{m} 2)$ and LE is the latent heat flux associated with evaporation of water from soil, water and vegetation $(\mathrm{W} / \mathrm{m} 2)$. The applied SEBAL method consists of a physically based one-layer sensible heat transfer scheme and an empirical estimation scheme for soil heat flux. The soil heat flux is computed as an empirical fraction of the net radiation using surface temperature, surface albedo and the normalized vegetation index (NDVI), as the depending variables, see figure below.

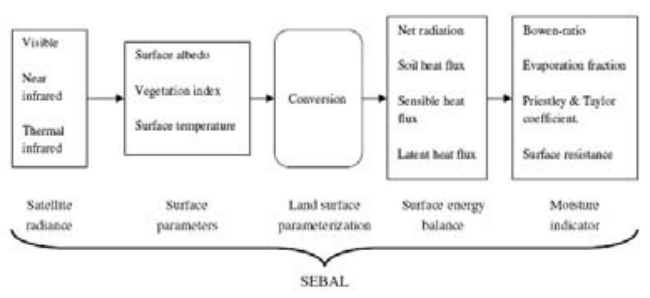

Figure 3: Conceptual Scheme for SEBAL showing its principal Components, Bastiaanssen et al, 1998.

\subsection{Estimating Energy Balance Components}

The surface energy balance is expressed as follows:

$$
R_{n}=H+L E+G_{o}
$$


Where: $R_{n}$ is the Net Radiation $\left(W m^{-2}\right), H$ is the sensible Heat flux $\left(W \mathrm{~m}^{-2}\right)$, LE the Latent Heat flux $\left(W m^{-2}\right)$ and $G_{o}$ the Soil Heat flux $\left(W m^{-2}\right)$.

\subsubsection{Net Radiation}

Net radiation is the electromagnetic balance of all the incoming and outgoing heat fluxes reaching and leaving a homogeneous flat surface and is usually expressed as follows:

$\mathrm{R}_{\mathrm{n}}=\mathrm{K}_{\downarrow}-\mathrm{K}^{\uparrow}+\mathrm{L}_{\downarrow}-\mathrm{L}^{\uparrow}$

Where: $\quad K$ is the short-wave and $L$ is the long-wave radiations respectively

$\mathrm{R}_{\mathrm{n}}=\mathrm{K}_{\text {net }}+\mathrm{L}_{\text {net }}$

$=(1-\alpha) \mathrm{K} \downarrow+\varepsilon_{\mathrm{a}} \sigma \mathrm{T}_{\mathrm{a}}^{4}-\varepsilon_{0} \sigma \mathrm{T}_{0}^{4}$

$=(1-\alpha) \mathrm{K} \downarrow+\varepsilon_{\mathrm{a}} \sigma \mathrm{T}_{\mathrm{a}}{ }^{4}-\left(1-\varepsilon_{0}\right) \varepsilon_{\mathrm{a}} \sigma \mathrm{T}_{\mathrm{a}}{ }^{4}-\varepsilon_{0} \sigma \mathrm{T}_{0}{ }^{4}$

Where: $\varepsilon$ is the surface emissivity, $\sigma$ is the StefanBoltzmann constant $\left(5.67 * 10-8\right.$ W.m-2K-4), $T_{a}$ is the air temperature $(K)$ and $T_{o}$ is the land surface temperature $(K)$.

\subsubsection{Soil Heat Flux}

The soil heat flux was computed using a relationship between the net radiation, surface temperature, surface albedo and NDVI, Kustas, et al, 2004

$$
G_{o}=c_{G} * \cos \theta * R_{n} * \exp \left(\frac{-\kappa L A I}{\sqrt{2 * \cos \theta}}\right)
$$

Where: $G_{o}$ is the soil heat flux, $C_{G}$ and $\kappa$ are constants 0.35 and 0.6 respectively, $R_{n}$ is net radiation as measured on the earth surface, $\theta$ is the solar zenith angle and LAI is Leaf Area Index

Koloskov (2007), however, observed that, over a 24-hour period, the soil heat flux could relatively be small and can be ignored without introducing significant errors in the computation process.

\subsubsection{Sensible Heat Flux}

This is the rate of heat loss to the air by convection and conduction, due to a temperature difference. Sensible heat flux is a function of the temperature gradient, surface roughness and wind speed and thus difficult to compute due to the fact that temperature gradient and surface roughness are a function of each other and hence at any time there are two unknowns in this functional relationship. The classical expression for sensible heat flux is given as (Farah and Bastiaanssen, 2001):

$$
H=\frac{\rho_{a} C_{p}}{r_{a h}} \partial T_{a}
$$

And $r_{a h}=\int_{Z_{\text {down }}}^{Z_{u p}} \frac{1}{K_{h}} d z=\left[\frac{1}{k u_{*}} \ln \left(\frac{Z_{u p}}{Z_{\text {down }}}\right)\right] \ldots$

Where: $\rho_{a}$ is the moist air density $\left(\mathrm{Kg} \mathrm{m}^{-3}\right), C_{p}$ is the specific heat capacity of air at constant pressure $\left(J \mathrm{Kg}^{-1} \mathrm{~K}^{-1}\right), \quad r_{a h}$ is the aerodynamic resistance to heat transport $\left(s \mathrm{~m}^{-1}\right)$ and $\delta T_{a}$ is the temperature difference between two heights $Z_{\text {down }}$ and $Z_{u p}(m), K_{h}$ is the eddy diffusivity for heat transport, $u^{*}$ is the friction velocity $\left(\mathrm{m} \mathrm{s}^{-1}\right)$ and $k$ is the von Karman's constant.

The presence of hydrological extremes in the area covered by the image was crucial for specific solutions for the surface energy balance. By assuming negligible sensible heat fluxes, $R_{n}$ $=\mathrm{G}_{0}+\mathrm{LE}$ was assigned for the wet pixels. This means that, $\mathrm{dT}_{\mathrm{a}}$ for the wet pixel $=0$ and $\mathrm{dT}_{\mathrm{a}}$ for the dry pixel $=((\mathrm{Rn}+$ $\left.\left.\mathrm{G}_{0}\right) \mathrm{r}_{\mathrm{ah}}\right) / \mathrm{p}_{\mathrm{a}} \mathrm{c}_{\mathrm{p}}$ and this relationship was used for the determination $\mathrm{dT}_{\mathrm{a}}$ for the dry pixel using the initial estimate for $r_{\mathrm{ah}}$.

It was also assumed $\mathrm{dT}_{\mathrm{a}}$ is linearly related to $\mathrm{T}_{0}$ at all pixels thus first estimate for the sensible heat flux was computed and subsequently used to obtain the integrated stability correction using Monin-Obukhov similarity hypothesis.

$$
L=\frac{-\rho_{a} C_{p} u_{*}^{3} T_{o}}{k g H} \ldots \ldots . .
$$

This allowed for a second and improved estimation of $\mathrm{u}^{*}$ incorporating the stability correction for buoyancy effect on the momentum flux. The new value of $u^{*}$ was then used to estimate $\mathrm{r}_{\mathrm{ah}}$ incorporating the stability correction for heat transport. This procedure was iteratively applied until $\mathrm{H}$ converges to the local non-neutral buoyancy conditions for each pixel. The energy balance was finally closed by considering the latent heat flux term as the residual term.

\subsubsection{Latent Heat Flux}

The latent heat flux represents the energy required for evapotranspiration and is computed as the residual of the surface energy balance. By therefore closing the energy budget on pixel-by-pixel basis Latent heat flux was obtained as follows:

$$
\mathrm{LE}=\mathrm{R}_{\mathrm{n}}-\mathrm{H}-\mathrm{G}
$$

The conversion of instantaneous flux values determined above for the satellite overpass time to daily and average monthly evaporation rates is done by the evaporative fraction

$$
\wedge_{\text {inst }}=\frac{L E}{R_{n}-G}=\frac{L E}{L E+H}=\wedge_{\text {day }}
$$

The daily evapotranspiration was then obtained from expression below.

$$
E_{d a y}=\frac{R_{n} * \wedge_{d a y}}{\lambda \rho_{w}}
$$

\section{RESULTS AND DISCUSSION}

Actual evapotranspiration $\left(\mathrm{ET}_{\mathrm{a}}\right.$ ) for the 12th July 2000, 2003 and 2006 were computed by solving the surface energy balance. The spatio-temporal variation of the $\mathrm{ET}_{\mathrm{a}}$ ranged from $0 \mathrm{~mm} /$ day for bare soils and fallow land to $8 \mathrm{~mm} /$ day for the wetlands and 
dense forests. Bare soils include the degraded lands within the communial grazing areas for the postoral communities to the north of the basin due the overgrazing. Agricultural land classes produced varied ET with small scale farms having between 3 to $4 \mathrm{~mm} /$ day, commercial horticultural farms 6 to $7 \mathrm{~mm} /$ day, and large scale ranches with 5 to $6 \mathrm{~mm} /$ day. Dense woodlands have average $\mathrm{ET}_{\mathrm{a}}$ value of about $6.24 \mathrm{~mm} /$ day.

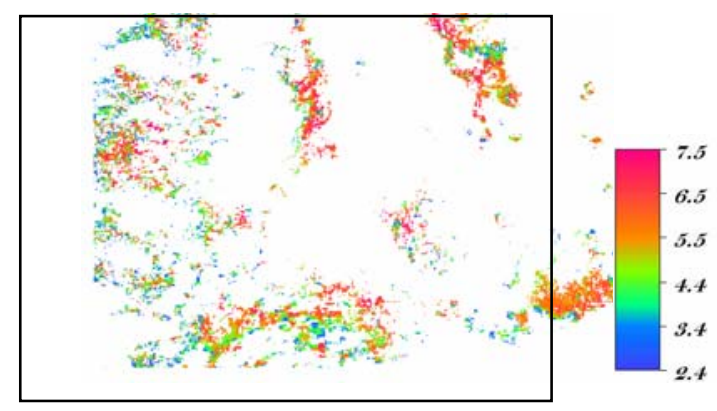

Figure 4a: Daily ET for 12th July, 2000

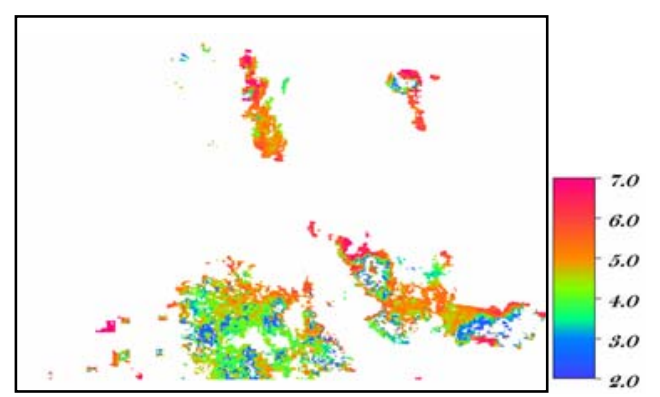

Figure4b: Daily ET for 12th July, 2003

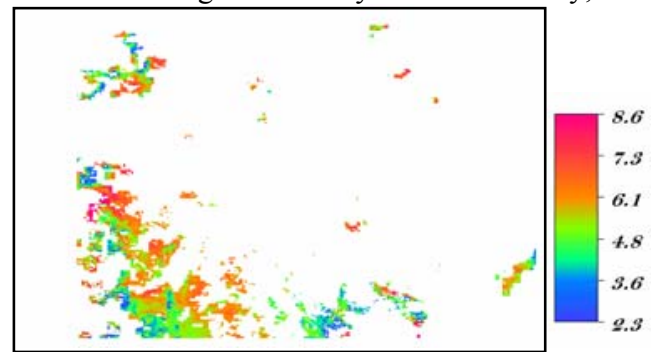

Figure 4c: Daily ET for 12th July, 2006

Actual evapotranpiration obtained from SEBAL were compared with ET values at six synoptic meteorological stations in the area calculated using FAO-56 method. Daily, monthly and seasonal values were compared and in each case, SEBAL overestimated. However the deviation varied from $20 \%$ for the daily estimates to about $5 \%$ for the seasonal estimates, and this was considered to be reasonable.

The daily $\mathrm{ET}_{\mathrm{a}}$ for the three time series were also compared with their respective NDVI values and a correlation of about $75 \%$ was obtained. The mean seasonal rainfall for the three time series was found to be almost the same but their distribution varied enormously across the years. It was found that the seasonal rainfall in 2000 was more spatially distributed as compared to 2003 and 2006 where more rainfall occurred to the southern part of the basin than to the north part, hence strongly influencing on the spatial distribution of the ET as indicated by Figure $4 \mathrm{a}, 4 \mathrm{~b}$ and $4 \mathrm{c}$.

\section{CONCLUSION}

The methodology applied in this paper enabled the estimation of the actual Evapotranspiration within the basin using MODIS satellite images. This information is different from FAO-56 calculated values, where land use, vegetation growth stages and meteorological data are used to model the Potential Evapotranspiration under assumed non-water stressed.

Though different, the results obtained in this study have shown that there is however a close agreement between the two approaches. This means that there is great potential in the use of remote sensing for estimating ET for practical application in water balance studies over larger areas.

\section{ACKNOWLEDGEMENTS}

The work reported here is part of the on going research on "Planning of System Innovations in Watersheds: Spatial Mapping of Environmental and Hydrological Determinants in Ewaso Ngiro North River Basins, Kenya", being funded by the Dutch government under the Netherlands Fellowship Programme and The International Institute for Geo-Information Science and Earth Observation (ITC). The authors wish to thank ITC, for the financial support to attend and present the results of this finding.

\section{REFERENCES}

Allen, R.G., Pereira, L.S., Raes, D., Smith, M., 1998. Crop evapotranspiration - Guidelines for computing crop water requirements - FAO Irrigation and drainage paper 56. FAO, Rome.

Bandara, K.M.P.S., 2003. Monitoring irrigation performance in Sri Lanka with high-frequency satellite measurements during the dry season. J. Agr. Water Manage. 58, 159-170.

Bastiaanssen W. G. M. 2000. SEBAL-Based Sensible and latent heat fluxes in the irrigated Gediz Basin, Turkey. Journal of Hydrology 229: 87-100.

Bastiaanssen W. G. M., Menenti M., Feddes R. A. and A.A.M. Holtslag A. A. M. 1998a. A remote sensing Surface Energy Balance Algorithm for Land (SEBAL), Part 1: Formulation. Journal of Hydrology 212-213: 198-212.

Bastiaanssen W.G.M., Pelgrum H., Wang J., Ma Y., Moreno J., Roerink G.J. van der Wal T. 1998b. The Surface Energy Balance Algorithm for Land (SEBAL), Part 2: Validation, Journal of Hydrology 212-213: 213-229.

Bastiaanssen, W.G.M., E.J.M. Noordman, H., Pelgrum, G., Davids, B.P., Thoreson, and R.G. Allen. .2005. SEBAL Model with Remotely Sensed Data to Improve Water-Resources Management under Actual Field Conditions. ASCE J. of Irrigation and Drainage Engineering 131(1):85-93.

Bastiaanssen W.G.M. 1995.

Regionalization of surface flux densities and moisture indicators in composite terrain. $\mathrm{PhD}$ thesis. Agricultural University, Wageningen, The Netherlands, p. 288

Bastiaanssen W.M.G. 2000. SEBAL-based sensible and latent heat fluxes in the irrigated Gediz Basin, Turkey. Journal of 
Hydrology 229:87-100

Chemin, Y., Platonoy, A., UI-Hassan, M., Abdullaey, I., 2004. Using Remote Sensing data for water depletion assessment at Administrative and Irrigation system levels. J. Agr. Water Manage. 64 (3), 183-196.

Decurtins, S., (1992). Hydro-geological Investigations in the Mt. Kenya Sub-catchment of the Ewaso Ng'iro River. African Study Series, A6. Geographica Bernensia. University of Bern, Switzerland.

Farah, O.H., Bastiaanssen W.G.M. 2001. Impact of spatial variation of land surface parameters on the regional evaporation case study with remote sensing. Hydrological Processes $15: 1585-1607$

Hemakumara, H.M., Chandrapala, L., Moene, F.A. 2003. Evapotranspiration fluxes over mixed vegetation areas measured from large aperture scintillometer. Agricultural Water Management 58:109-122

Koloskov G., Mukhamejonav K.H., Tanto T.W. 2007. MoninAbukhov length as a cornerstone of the SEBAL calculations of evapotranspiration. Journal of Hydrology 335:170-179

Kustas W.P., Norma J.M., Schmugge T.J., Anderson M.C. 2004. Mapping surface energy balance fluxes with radiometric temperature. In D.A Quattrochi and J.C Luvali (Eds.), Thermal remote sensing in land surfaces processes (pp. 205-253). Boca Raton. Florida: CRC Press

Wu. W , Hall. C.A.S., Scatena. F.N., Quackenbush. L. J. 2006. Spatial modelling of evapotranspiration in the Luquillo experimental forest of Puerto Rico using remotely-sensed data. Journal of Hydrology 328, 733- 752 
